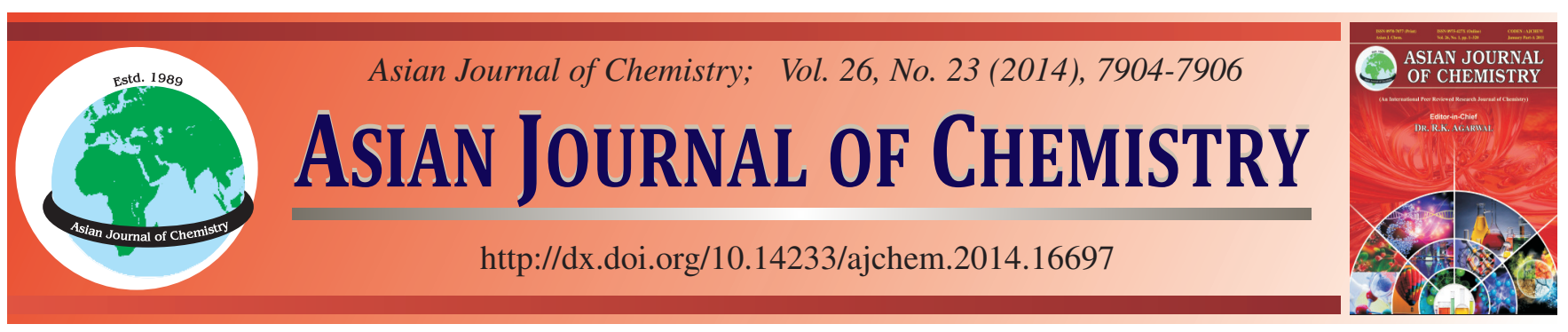

\title{
Microwave Assisted Synthesis of Pyridin-1-ium Salt of 6-Nitroquinazolin-4-one and its 6-Amino Analog under Ultrasonic Irradiation
}

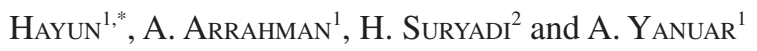

${ }^{1}$ Pharmaceutical Chemistry Laboratory, Faculty of Pharmacy, University of Indonesia, Depok 16424, West Java, Indonesia

${ }^{2}$ Microbiology Laboratory, Faculty of Pharmacy, University of Indonesia, Depok 16424, West Java, Indonesia

*Corresponding author: Fax: +62 21 7863433; Tel: +62 21 7270031; E-mail: hayun.ms@ui.ac.id

\begin{abstract}
The new compounds of quinazolin-4-one derivative i.e., 2-methyl-6-nitroquinazolin-4-one substituted pyridin-1-ium salt at methyl group and its 6-amino analog have been synthesized. Microwave irradiation of solution of 2-bromomethyl-6- nitroquinazolin-4-one and pyridine in acetonitrile for $3 \mathrm{~min}$ afforded 1-[(6-nitroquinazolin-4-one-2-yl)methyl]pyridin-1-ium bromide; and nitro reduction of the product with iron in ethanol/acetic acid/water under ultrasonic irradiation afforded 1-[(6-aminoquinazolin-4-one-2-yl)methyl]pyridin-1-ium bromide. The structure of the synthesized compounds were confirmed on the basis of FT-IR, ${ }^{1} \mathrm{H}$ NMR and ${ }^{13} \mathrm{C}$ NMR data.
\end{abstract}

Keywords: Pyridinium salt, Quinazolin-4-one, 6-Nitroquinazolin-4-one, 6-Aminoquinazolin-4-one, Ultrasound,Aqueous media, Microwave. ᄂ - - - - - - - - - - - - - - - - - - - - - - - - - - -

\section{INTRODUCTION}

4(3H)-Quinazolinone derivatives are the important class of heterocycles. They possess various biological activities such as antibacterial, antiinflammation, antihistaminic, etc., depend on the substituents at the ring system ${ }^{1-3}$. On the other hands, some of pyridium salts exhibit antibacterial acitivity. The pyridinium salts of phenacyl were obtained by the reaction of phenacyl halide in chloroform at room temperature for overnight at a dark place, while the pyridium salts of alkyl were obtained by the reaction of corresponding alkyl halide and pyridines in appropriate solvents, heated at reflux for 6-50 $\mathrm{h}^{4-6}$. Microwave (MW) and ultrasonic irradiation has attracted considerable attention for rapid synthesis of organic compounds $s^{7-9}$. In this paper, we report the microwave assisted synthesis of 1-[(6-nitroquinazolin-4-one-2-yl)methyl]pyridin-1ium bromide and synthesis of its 6-amino analog under ultrasonic irradiation.

\section{EXPERIMENTAL}

All the solvents, reagents and chemicals are analytical grade and were used without purification. Microwave irradiation was performed using modified home microwave oven completed with reflux condensor. The purity of the products was tested using TLC method. Melting points were determined in capillary tube using melting point apparatus (Stuart Scientific) and are uncorrected. Infrared (IR) spectra were recorded on a FTIR spectrophotometer (8400S, Shimadzu) and ${ }^{1} \mathrm{H}$ NMR and ${ }^{13} \mathrm{C}$ NMR spectra were recorded on a NMR spectrometer (JEOL JNM 500) using TMS as the internal standard. Physical data and analytical data of the synthesized compounds are given in Tables 1 and 2, respectively.

\begin{tabular}{cccc}
\multicolumn{4}{c}{ TABLE-1 } \\
\multicolumn{5}{c}{ PHYSICAL DATA OF THE SYNTHESIZED COMPOUNDS } \\
\hline Compound & Yield $(\%)$ & \multicolumn{1}{c}{ Form } & m.p. $\left({ }^{\circ} \mathrm{C}\right)$ \\
\hline $\mathbf{1}$ & 44.0 & White crystalline powder & $240-242$ \\
$\mathbf{2}$ & 54.0 & White crystalline powder & $235-236$ \\
$\mathbf{3}$ & 82.5 & Yellow powder & $222-223$ \\
$\mathbf{4}$ & 94.0 & White crystalline powder & $245-246$ \\
$\mathbf{5}$ & 64.0 & Pale yellow powder & $224-225$ \\
\hline
\end{tabular}

Synthesis of methyl-4(3H)-quinazolinone (1): Compound 1 was synthesized under microwave irradiation according to reported method ${ }^{10-11}$.

Synthesis of 2-(bromomethyl-4(3H)-quinazolinone (2): Compound $\mathbf{2}$ was synthesized by treatment of solution of $\mathbf{1}$ in dimethylformamide (DMF) with $\mathrm{N}$-bromosuccinimide $(\mathrm{NBS})^{12}$.

Synhtesis of 2-(bromomethyl)-6-nitro-4(3H)-quinazolinone (3): Compound 3 was synthesized by nitration of $\mathbf{2}$ according to reported method for nitro derivatives synthesis of quinazolin-4-one ${ }^{13,14}$. To a solution of 2-(bromomethyl)$4(3 \mathrm{H})$-quinazolinone $(2,6.93 \mathrm{~g}, 30 \mathrm{mmol})$ in concentrated sulfuric acid $90 \mathrm{~mL}$, fuming nitric acid $(7.5 \mathrm{~mL})$ was added dropwise at $0{ }^{\circ} \mathrm{C}$. The reaction mixture was stirred at room temperature for $4 \mathrm{~h}$ and then poured into crushed ice $(200 \mathrm{~mL})$. 


\begin{tabular}{|c|c|c|}
\hline \multicolumn{3}{|c|}{$\begin{array}{c}\text { TABLE-2 } \\
\text { IR AND NMR DATA OF THE SYNTHESIZED COMPOUNDS }\end{array}$} \\
\hline Compd. & IR $v_{\max }\left(\mathrm{cm}^{-1}\right)$ & $\operatorname{NMR}(\delta, \mathrm{ppm})$ \\
\hline 1 & $\begin{array}{l}\text { 3,170 (N-H lactam), } 3047 \text { (ArC-H str), } 2918 \text { (AlC-H str), } \\
1,689(\mathrm{C}=\mathrm{O} \text { lactam }), 1,612(\mathrm{C}=\mathrm{N})\end{array}$ & $\begin{array}{l}11.75 \text { broad }(1 \mathrm{H}, \mathrm{s}, \mathrm{NH}), 8.28(1 \mathrm{H}, \mathrm{dd}, J=8.4 ; 1.9, \mathrm{H}-5), 7,77(1 \mathrm{H}, \mathrm{td}, J= \\
8.2 ; 1,8, \mathrm{H}-7), 7.68(1 \mathrm{H}, \mathrm{d}, J=9.0, \mathrm{H}-8), 7.48(1 \mathrm{H}, \mathrm{t}, J=8.4, \mathrm{H}-6), 2.60 \\
\left(3 \mathrm{H}, \mathrm{s}, \mathrm{CH}_{3}\right)\end{array}$ \\
\hline 2 & $\begin{array}{l}\text { 3,175 (N-H lactam), 3,030 (ArC-H str), 2,924 (AlC-H } \\
\text { str), 1,689 (C=O lactam), 1,608 (C=N), } 804(\mathrm{C}-\mathrm{Br})\end{array}$ & $\begin{array}{l}12.58 \operatorname{broad}(1 \mathrm{H}, \mathrm{s}, \mathrm{NH}), 8.11(1 \mathrm{H}, \mathrm{d}, J=10 \mathrm{~Hz}, \mathrm{H}-5), 7.66(1 \mathrm{H}, \mathrm{d}, J= \\
7.8 \mathrm{~Hz}, \mathrm{H}-8), 7.83(1 \mathrm{H}, \mathrm{t}, J=7.1 \mathrm{~Hz}, \mathrm{H}-6), 7.54(1 \mathrm{H}, \mathrm{t}, \mathrm{J}=7.8, \mathrm{H}-7), 4,40 \\
\left(2 \mathrm{H}, \mathrm{s}, 2-\mathrm{CH}_{2}\right)\end{array}$ \\
\hline 3 & $\begin{array}{l}\text { 3,189 (NH lactam), 3,030 (ArC-H str), 2,924 (AlC-H } \\
\text { str), 1,682 (C=O lactam), 1,616 (C=N), 1,467 }\left(\mathrm{CH}_{2} \mathrm{sci}\right) \\
1,577,1,491(\text { ArC }=\mathrm{C}), 1,521,1,342\left(\mathrm{NO}_{2}\right), 795(\mathrm{C}-\mathrm{Br})\end{array}$ & $\begin{array}{l}13.12 \text { broad }(1 \mathrm{H}, \mathrm{s}, \mathrm{NH}), 8.79(1 \mathrm{H}, \mathrm{d}, J=1.9 \mathrm{~Hz}, \mathrm{H}-5), 8.56(1 \mathrm{H}, \mathrm{dd}, J= \\
8.2,1.9 \mathrm{~Hz}, \mathrm{H}-7), 7.87(1 \mathrm{H}, \mathrm{d}, J=9.0 \mathrm{~Hz}, \mathrm{H}-8), 4,44\left(2 \mathrm{H}, \mathrm{s}, 2-\mathrm{CH}_{2}\right)\end{array}$ \\
\hline 4 & $\begin{array}{l}3,134(\mathrm{~N}-\mathrm{H} \text { lactam }), 3,045(\mathrm{ArC}-\mathrm{H} \text { str }), 2,955-2,862(\mathrm{Al} \\
\mathrm{C}-\mathrm{H} \text { str }), 1,699(\mathrm{C}=\mathrm{O} \text { lactam }), 1,614(\mathrm{C}=\mathrm{N}), 1,579,1,493 \\
(\mathrm{ArC}=\mathrm{C}), 1,464\left(\mathrm{CH}_{2} \text { sci) } 1,521,1,348\left(\mathrm{NO}_{2}\right), 769,717\right. \\
\text { (C-H bend })\end{array}$ & 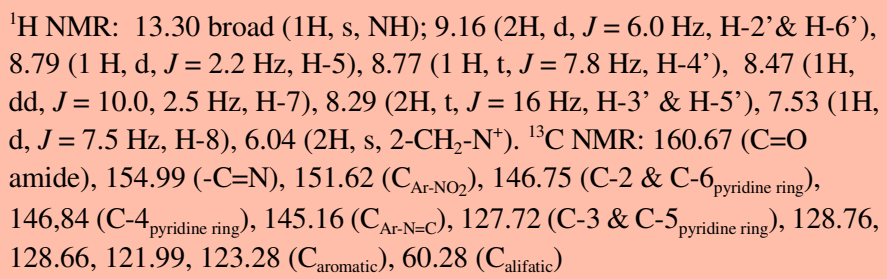 \\
\hline 5 & $\begin{array}{l}3423,3298\left(\mathrm{NH}_{2}\right), 3,134(\mathrm{~N}-\mathrm{H} \text { lactam }), 3,050(\mathrm{ArC}-\mathrm{H} \\
\text { str }), 2,960-2,858(\mathrm{AlC}-\mathrm{H} \text { str }), 1,672(\mathrm{C}=\mathrm{O} \text { lactam }), 1,633 \\
(\mathrm{C}=\mathrm{N}), 1,562,1491(\mathrm{ArC}=\mathrm{C}), 1,435\left(\mathrm{CH}_{2} \text { sci }\right), 794 \\
\text { (primary Ar-amine), 740, } 694(\mathrm{C}-\mathrm{H} \text { bend })\end{array}$ & 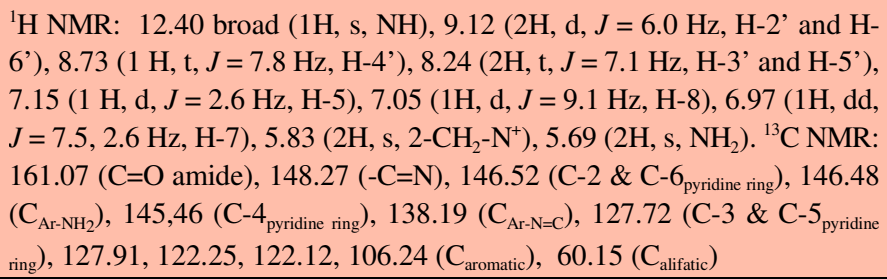 \\
\hline
\end{tabular}

A precipitate was filtered, washed with water and dried in vacuum drying oven at $70{ }^{\circ} \mathrm{C}$ for $1 \mathrm{~h}$.

1-[(6-Nitroquinazolin-4-one-2-yl)methyl]pyridin-1ium bromide (4): Solution of $3(690 \mathrm{mg}, 2.5 \mathrm{mmol})$ and pyridine $2 \mathrm{~mL}$ in acetonitrile $150 \mathrm{~mL}$ was irradiated under microwave for $3 \mathrm{~min}$ at power level $30 \%$. The precipitate formed was filtered off, washed with cold acetonitrile and dried in vacuum drying oven at $70{ }^{\circ} \mathrm{C}$ for $1 \mathrm{~h}$.

1-[(6-Aminoquinazolin-4-one-2-yl)methyl]pyridin-1ium bromide (5): Compound $\mathbf{5}$ was synthesized by reduction of $\mathbf{4}$ using modified method of aryl nitro reduction reported by Gamble et al. ${ }^{9}$. To a suspension of $4(182 \mathrm{mg}, 0.5 \mathrm{mmol})$ in a mixture of glacial acetic acid $(1 \mathrm{~mL})$, ethanol $(2 \mathrm{~mL})$ and water $(1 \mathrm{~mL})$ was added reduced iron powder $(0.140 \mathrm{~g}, 2.5$ $\mathrm{mmol}$ ). The resulting suspension was exposed to ultrasonic irradiation for $1 \mathrm{~h}$ at $30^{\circ} \mathrm{C}$ with TLC analysis monitoring for the completion of the reaction. The reaction mixture was filtered to remove the iron residue and the filtrate obtained was diluted with ethanol and added concentrated ammonia solution to precipitate iron salts. The resulting mixture was filtered through cellite and solvent of the filtrate was evaporated under reduced pressure. The crude residue was then recrystallized from methanol.

\section{RESULTS AND DISCUSSION}

The titled compounds (4 and $\mathbf{5}$ ) were synthesized stepwise summarized in Fig. 1. In the first step, anthranilic acid was reacted with acetic anhydride $\left(\mathrm{Ac}_{2} \mathrm{O}\right)$ under microwave irradiation for $10 \mathrm{~min}$ at power level $30 \%$. Ammonium acetate was added and the microwave irradiation at power level $30 \%$ was continued for $10 \mathrm{~min}$ to provide 2-methylquinazolinon4-one (1). This compound was then treated with NBS in DMF to obtain 2-bromomethylquinazolin-4-one (2). Nitration of $\mathbf{2}$ with fuming nitric acid in concentrated sulfuric acid at room temperature to obtain 2-bromomethyl-6-nitroquinazolin-4-one (3) and then microwave irradiation of solution of $\mathbf{3}$ and pyridine in acetonitrile at power level $30 \%$ for $3 \mathrm{~min}$ to provide $1-[(6-$ nitroquinazolin-4-one-2-yl)methyl]pyridin-1-ium bromide (4). In the last step, suspension of $\mathbf{4}$ in mixture of ethanol, glacial acetic acid and water was reduced with iron under sonication at $30^{\circ} \mathrm{C}$ for $1 \mathrm{~h}$ to get 1 -[(6-aminoquinazolin-4-one-2-yl)methyl]pyridin-1-ium bromide (5).

The IR spectrum of the title compound $\mathbf{4}$ showed absorption bands at 3,134 and $1,699 \mathrm{~cm}^{-1}$ due to the pesence of N-H and $\mathrm{C}=\mathrm{O}$ lactam, respectively; $3,045 \mathrm{~cm}^{-1}$ (aromatic $\mathrm{C}-\mathrm{H}$ ), 2,955-2,862 $\mathrm{cm}^{-1}$ (alipatic C-H), 1,614 $\mathrm{cm}^{-1}(\mathrm{C}=\mathrm{N}), 1,521$ and $1,348 \mathrm{~cm}^{-1}\left(\mathrm{NO}_{2}\right)$. In the ${ }^{1} \mathrm{H}$ NMR spectrum, a proton of $\mathrm{NH}$ lactam appeared as one broad singlet at $\delta 13.30 \mathrm{ppm}$; and the three protons of quinazolinone ring are observed as two doublets at $\delta 8.79 \mathrm{ppm}(1 \mathrm{H}, J=2.2 \mathrm{~Hz}, \mathrm{H}-5)$ and at $\delta 7.53$ $\operatorname{ppm}(1 \mathrm{H}, J=7.5 \mathrm{~Hz}, \mathrm{H}-8)$ and as one double doublet at $\delta 8.47$ ppm $(1 \mathrm{H}, J=10,2.5 \mathrm{~Hz}, \mathrm{H}-7)$. Five protons of pyridine ring are observed as one doublet at $\delta 9.16 \mathrm{ppm}\left(2 \mathrm{H}, J=6 \mathrm{~Hz}, \mathrm{H}-2^{\prime}\right.$ and $\left.\mathrm{H}-6^{\prime}\right)$, as two triplets at $\delta 8.29 \mathrm{ppm}\left(2 \mathrm{H}, J=16 \mathrm{~Hz}, \mathrm{H}-3^{\prime}\right.$ and $\left.\mathrm{H}^{-5}{ }^{\prime}\right)$ and at $\delta 8.77 \mathrm{ppm}\left(1 \mathrm{H}, J=7.8 \mathrm{~Hz}, \mathrm{H}-4^{\prime}\right)$, while two protons of the methyl group appear as a singlet at $\delta 6.04 \mathrm{ppm}$ $\left(2 \mathrm{H}, 2-\mathrm{CH}_{2}\right)$. The chemical shifts of proton of $\mathrm{CH}_{2}$ and pyridine ring were observed very downfield than that of $\mathrm{CH}_{2}$ of compound $\mathbf{3}$ and free pyridine ${ }^{15}$. These data indicated that compound 4 was quarternized (pyridinium) alkyl halide 6 . The IR spectrum of compound 5 showed absorption band at 3,423, 3,298 and $794 \mathrm{~cm}^{-1}$, while the bands at 1,521 and $1,348 \mathrm{~cm}^{-1}$ disappeared. This data confirmed that nitro group of compound 4 was reduced to be primary amine group. In the ${ }^{1} \mathrm{H}$ NMR spectrum, two proton of primary amine appeared as singlet at 


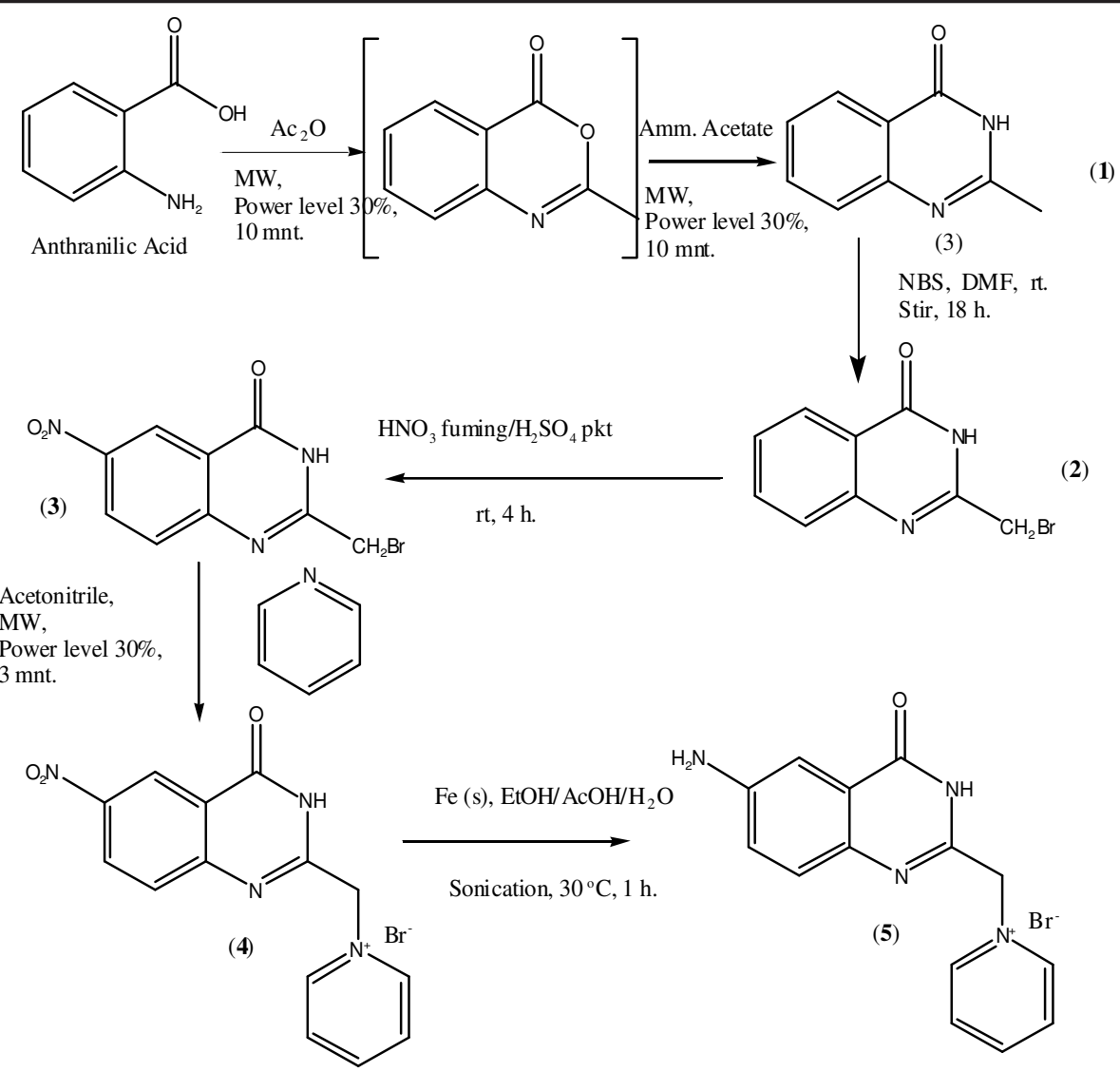

Fig. 1. Schematic reaction of the synthesis of the titled compounds (4 and 5)

$\delta 5.69 \mathrm{ppm}\left(2 \mathrm{H}, \mathrm{NH}_{2}\right) .{ }^{13} \mathrm{C}$ NMR spectra of compound 4 and 5 as indicated in Table- 1 confirmed the proposed structures.

\section{Conclusion}

In conclusion, reactions of 2-(bromomethyl)-6-nitroquinazolin-4-one and pyridine in acetonitrile under microwave irradiation at power level $30 \%$ for 3 min afforded 1-[(7-nitro1-oxo-1,2-dihydroisoquinolin-3-yl)methyl]pyridin-1-um (4) and the reduction of $\mathbf{4}$ with iron powder in mixture of ethanol, glacial acetic acid and water under sonication irradiation for $1 \mathrm{~h}$ afforded 1-[(7-amino-1-oxo-1,2-dihydroisoquinolin-3yl)methyl]pyridin-1-um (5).

\section{ACKNOWLEDGEMENTS}

The authors thank the Directorate of Research and Community Service, University of Indonesia, Depok, Indonesia, for the financial support of this research; and also to Research Center for Chemistry of the Indonesian Institute of Science, Serpong, Indonesia, for recording NMR spectral data.

\section{REFERENCES}

1. D.J. Connolly, D. Cusack, T.P. O'Sullivan and P.J. Guiry, Tetrahedron, 61, 10153 (2005).
2. S.R. Pattan, Indian J. Chem., 45B, 1778 (2006).

3. M. Srivastav, MD. Salahuddin and S.M. Shantakumar, E-J. Chem., 6, 1055 (2009).

4. S. Hameed, M. Saeed, A. Khan, M. Ahmed, S.S. Nizami and M.H. Kazmi, J. Islamic Ac. Sci., 7, 26 (1994).

5. R.N. Jayatissa, R.P. Perera, C.M. Hettiarachchi and P.M. Weerawarna, Indian J. Microbiol., 52, 83 (2012).

6. V. Alptüzün, S. Parlar, H. Tasli and E. Erciyas, Molecules, 14, 5203 (2009).

7. Y. Ju and R.S. Varma, Green Chem., 6, 219 (2004).

8. C.O. Kappe and D. Dallinger, Drug Discovery, 5, 51 (2006).

9. A.B. Gamble, J. Garner, C.P. Gordon, S.M.J. O'Conner and P.A. Keller, Synth. Commun., 37, 2777 (2007).

10. S.S. Kotgire, S.K. Mahajan, S.V. Amrutkar and U.D. Bhagat, J. Pharm. Sci. Res., 2, 518 (2010).

11. M.S. Ranawat, S.V. Amrutkar and P. Phargharmol, Int. J. Drug Design Discovery, 2, 452 (2011).

12. C.M. Gupta, A.P. Bhaduri and N.M. Khanna, J. Med. Chem., 11, 392 (1968).

13. Y. Kabri, P. Verhaeghe, A. Gellis and P. Vanelle, Molecules, 15, 2949 (2010).

14. S. Sastradi, B.P, Maggadani and Hayun, Synthesis of Nitro Derivatives of 3-(4-Chlorophenyl)-2-methyl-4(3H)-quinazolinon, Proceeding ICICS-2013, Yogyakarta, Oct. 22-23 (2013).

15. R.M. Silverstein, G.C. Basseler and T.C. Morrill, Spectrometric Identification of Organic Compound, JohnWiley \& Sons, Inc., New York: edn. 5 (1991). 